\section{PELATIHAN PEMBUATAN ALAT PERAGA MATEMATIKA UNTUK SEKOLAH DASAR MEMANFAATKAN BAHAN BEKAS DI SD NEGERI OI PADANG AIR DINGIN}

Mirda Swetherly Nurva', Tiara Fikriani ${ }^{2}$

\author{
1,2)STKIP Ahlussunnah \\ * Mirda Swetherly Nurva \\ Email: mirdanurval I@gmail.com
}

\begin{abstract}
The object of mathematics is abstract, so that the math teacher must compose abstract mathematical objects to be easy learning for students. Solving this problem, experience through real objects (concrete) such as props is required. Using props, students can see, feel, and think directly about the object after they learn so that the abstract concept being studied can settle, cling, and last in the student's mind. This devotion aims to provide the ability to think mathematics creatively and develop a favourable attitude towards mathematical thinking. The methods of this devotional activity are lectures, $Q \& A$ and discussions. The results obtained after doing this activity have an impact on students' understanding. Students who understand the materials taught faster and then teachers are also more creative in utilizing used materials to learn media. Teachers do not have to spend much money to make an attractive prop.

Keywords: Props, used materials, Mathematical media
\end{abstract}

\begin{abstract}
Abstrak
Objek kajian matematika merupakan sesuatu yang abstrak sehingga guru matematika harus mampu mengkongkritkan objek matematika yang abstrak agar mudah dipelajarioleh siswa. Untuk mengatasi hal tersebut, diperlukan pengalaman melalui benda-benda nyata (konkrit) seperti alat peraga. Dengan menggunakan alat peraga siswa dapat melihat, meraba, dengan memikirkan secara langsung objek yang sedang mereka pelajari, sehingga konsep abstrak yang sedang dipelajari dapat mengendap, melekat dan tahan lama di pikiran siswa. Tujuan dari pengabdian ini adalah Memberikan kemampuan berpikir matematika secara kreatif dan Mengembangkan sikap yang menguntungkan ke arah berpikir matematika. Metode dari kegiatan pengabdian ini adalah ceramah, Tanya jawab dan diskusi. Hasil yang diperoleh setelah melakukan kegiatan ini berdampak pada pemahaman siswa. Siswa lebih cepat paham tentang maetri yang diajarkan. Disamping itu, guru juga semakin kreatif dalam memanfaatkan bahan bekas untuk dijadikan media pembelajaran. Guru tidak perlu mengeluarkan biaya yang begitu besar untuk membuat sebuah alat peraga yang menarik. Kata Kunci: Alat peraga, bahan bekas, Media matematika
\end{abstract}


PELATIHAN PEMBUATAN ALAT PERAGA MATEMATIKA UNTUK SEKOLAH DASAR MEMANFAATKAN

BAHAN BEKAS DI SD NEGERI O1 PADANG AIR DINGIN

Mirda Swetherly Nurva, Tiara Fikriani

Volume 1, No. 1, April 2021 hal. 102-108

DOI Artikel : 10.46306/jub.v1i1.20

\section{PENDAHULUAN}

Belajar matematika merupakan kegiatan mental yang tinggi, sebab matematika berkaitan dengan konsep-konsep yang abstrak yang berkenaan dengan ide-ide, struktur- struktur dan hubunganhubungan yang diatur secara logis yang akan membawa terjadinya proses pembelajaran matematika itu. Objek kajian matematika merupakan sesuatu yang abstrak sehingga guru matematika harus mampu mengkongkritkan atau menyederhanakan objek matematika yang abstrak agar mudah dipelajarioleh siswa.

Untuk mengatasi hal tersebut, maka dalam mempelajari suatu objek dalam pembelajaran matematika diperlukan pengalaman melalui benda-benda nyata (konkrit) yaitu alat peraga yang dapat digunakan sebagai jembatan bagi siswa untuk berpikir anstrak. Alat peraga adalah segala sesuatu yang dapat digunakan untuk menyatakan pesan merangsang pikiran, perasaan, perhatian dan kemauan siswa sehingga dapat mendorong proses belajar (Ali, 20I4). Konsep abstrak matematika yang disajikan dalam bentuk konkrit akan lebih dapat dipahami dan dimengerti oleh siswa. Fungsi utama alat peraga adalah untuk menurunkan keabstrakan dari konsep, agar anak mampu menangkap arti sebenarnya dari konsep yang dipelajari. Dengan melihat, meraba, dan memanipulasi alat peraga maka anak mempunyai pengalaman nyata dalam kehidupan tentang arti konsep. Sedangkan sarana merupakan media pembelajaran yang fungsi utamanya sebagai alat bantu untuk melakukan pembelajaran. Dengan menggunakan sarana tersebut diharapkan dapak memperlancar pembelajaran. Contoh: papan tulis, jangka, penggaris, lembar tugas (LT), lembar kerja (LK), dan alat-alat permainan.

Dengan menggunakan alat peraga siswa dapat melihat, meraba, mengungkapkan dengan memikirkan secara langsung objek yang sedang mereka pelajari, sehingga konsep abstrak yang sedang dipelajari dapat mengendap, melekat dan tahan lama dibenak pikiran siswa. Penggunaan alat peraga dapat dikaitkan dengan aspek penanamankonsep, pemahaman konsep serta pembinaan ketrampilan dan juga meningkatkan motivasi belajar siswa. Berdasarkan Permendiknas Nomor 22 tahun 2006 tentang Standar Isi menyebutkan bahwa matematika dipelajari mulai dari pendidikan dasar (permendiknas, 2006). oleh karena itu agar siswa dapat memahami matematika dengan baik maka diperlukan pemahaman konsep-konsep dasar dalam matematika.

Alat peraga pembelajaran matematika merupakan bagian dari media pembelajaran. Levie \& Lentz dalam Azhar Arsyad, mengemukakan terdapat empat fungsi media pembelajaran menggunakan alat peraga, khususnya media visual, yaitu :

I. Fungsi atensi, media visual merupakan inti, yaitu menarik dan mengarahkan siswa untuk berkonsentrasi kepada isi pelajaran.

2. Fungsi afektif, media dapat terlihat dari tingkat kenikmatan siswa ketika belajar (atau membaca) teks yang bergambar. Gambar atau lambang visual dapat mengubah emosi dan sikap siswa, misalnya informasi menyangkut masalah sosial. 
PELATIHAN PEMBUATAN ALAT PERAGA MATEMATIKA UNTUK SEKOLAH DASAR MEMANFAATKAN

BAHAN BEKAS DI SD NEGERI O1 PADANG AIR DINGIN

Mirda Swetherly Nurva, Tiara Fikriani

Volume 1, No. 1, April 2021 hal. 102-108

DOI Artikel : 10.46306/jub.v1i1.20

3. Fungsi kognitif, media dapat terlhat dari temuan-temuan penelitian yang menggunakan bahwa lambang visual atau gambar memperlancar pencapaian informasi atau pesan yang terkandung dalam gambar.

4. Fungsi kompensatoris, media pembelajaran terlihat dari hasil penelitian bahwa media yang memberikan konteks untuk memahami teks membantu siswa yang lemah dalam membaca atau mengorganisasikan informasi dalam teks dan mengingatnya kembali (Arsyad, 20I I)

Apabila media pembelajaran dapat memberikan pengalaman belajar yang bermakna, maka hal ini dapat mengaktifkan dan menyenangkan anak. Pengalaman anak dalam proses belajar mengajar sangatlah penting. Dengan demikian alat bantu belajar atau biasa disebut media akan berfungsi dengan baik. Dapat dikatakan bahwa media pembelajaran matematika memiliki peranan sangat besar untuk menyampaikan konsep-konsep dasar matematika maupun bagi peserta didik dalam menerima pengetahuan yang disampaikan guru kepadanya.

Dalam pembelajaran matematika, penggunaan alat peraga juga dapat meningkatkan motivasi belajar siswa. Hal ini sesuai dengan pendapat Erman Suherman yang mengungkapkan bahwa dalam pembelajaran matematika kita sering menggunakan alat peraga, dengan menggunakan alat peraga, maka: I. Proses belajar mengajar termotivasi. Baik siswa maupun guru, dan terutama siswa, minatnya akan timbul. la akan senang, terangsang, tertarik, dank arena itu akan bersikap positif terhadap pembelajaran matematika. 2. Konsep abstrak matematika tersajikan dalam bentuk konkrit dan karena itu lebih dapat dipahami dan dimengerti, dan dapat ditanamkan pada tingkat-tingkat yang lebih rendah. 3. Hubungan antara konsep abstrak matematika dengan bendabenda di alam sekitar akan lebih dapat dipahami. 4. Konsep-konsep abstrak yang tersajikan dalam bentuk konkrit yaitu dalam bentuk model matematik yang dapat dipakai sebagai objek penelitian maupun sebagai alat untuk meneliti ide-ide batu dan relasi baru menjadi bertambah banyak. (Suherman, 2003)

Suatu fakta yang patut direnungkan dan disadari sepenuhnya untuk dilakukan tindak lanjut secara nyata bagi semuanya yang terlibat di dunia pendidikan bahwa: pengajaran matematika SD menggunakan alat peraga dan media lainnya secara tepat dibandingkan dengan yang tanpa menggunakan adalah enam berbanding satu Artinya penggunaan alat peraga dan media lainnya dalam pembelajaran matematika (khususnya dalam memberikan penanaman konsep) akan membawa hasil enam kali lebih baik dan lebih cepat dibandingkan dengan pengajaran drill tanpa konsep (Prof. Dr. Ruseffendi, M.Sc. pada Seminar Pengajaran Matematika SD saat lustrum Fak. MIPA ITB tahun I99I.

\section{METODE PENGABDIAN}

Metode yang diterapkan pada kegiatan ini adalah:

1) ceramah, metode ceramah dipilih untuk memberikan penjelasan materi pelatihan, dan

2) Tanya jawab, pada tahap ini dilakukan tanya jawab tentang materi untuk memperoleh gambaran 
PELATIHAN PEMBUATAN ALAT PERAGA MATEMATIKA UNTUK SEKOLAH DASAR MEMANFAATKAN

BAHAN BEKAS DI SD NEGERI 01 PADANG AIR DINGIN

Mirda Swetherly Nurva, Tiara Fikriani

Volume 1, No. 1, April 2021 hal. 102-108

DOI Artikel : 10.46306/jub.v1i1.20

sedalam dalamnya tentang penerimaan materi. Metode tersebut dapat terlaksana dengan baik apabila adanya interaksi dan timbal balik yang baik antara pemateri dan penerima materi. Tahap ini merupakan tahap pelatihan yang diberikan kepada para guru di SDN 0I Padang Air Dingin.

\section{PELAKSANAAN DAN PEMBAHASAN}

Pelaksanaan pelatihan ini mencakup beberapa hal berikut.

a) Persiapan Tahap persiapan merupakan tahap awal sebelum pelaksanaan PPM. Dalam tahap ini ada beberapa hal yang dilakukan, yaitu Koordinasi Internal, dilakukan oleh Tim, Penentuan dan rekruitment peserta pelatihan, Pembuatan Instrumen PPM, seperti lembar presensi, angket, lembar kerja, Pembuatan modul pelatihan Powerpoint, dan Persiapan konsumsi, publikasi, lokasi, dokumentasi, dsb.

b) Pelaksanaan Pelatihan Tahap ini merupakan tahap pelatihan yang diberikan kepada guru di SDN 0 I Padang Air Dingin.

c) Penyajian Materi Materi yang disajikan terkait dengan pengenalan dan penggunaan program Powerpoint untuk pembuatan media pembelajaran. Penyaji materi adalah tim pengabdi sendiri.

d) Refleksi dan Penutupan Program PPM Akhir kegiatan peserta dan Tim melakukan refleksi hasil pelatihan dan para peserta juga memberikan evaluasi akan pelatihan ini. Guru diminta untuk membuat draft rancangan alat peraga yang akan digunakan. Lalu diminta mengumpulkan ke pemateri untuk dibahas bersama audiens.

e) Evaluasi Kegiatan Evaluasi kegiatan PPM ini dilakukan dengan beberapa cara. Evaluasi hasil dilihat dari tugas praktik para peserta yang ada. Hasil praktiknya dinilai dan hal itu menggambarkan keberhasilan materi yang telah disajikan. Selain itu, secara proses juga dicermati kinerja dan kesertaan para peserta. Di akhir kegiatan Tim menjaring data kebermaknaan program pada para peserta. Untuk foto kegiatan, dapat dilihat pada Gambar berikut :

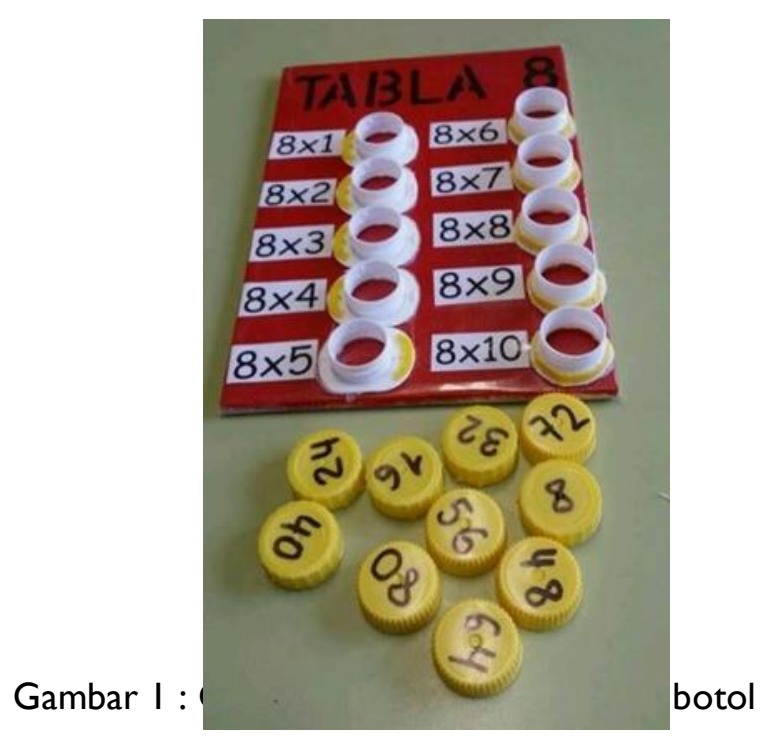


PELATIHAN PEMBUATAN ALAT PERAGA MATEMATIKA UNTUK SEKOLAH DASAR MEMANFAATKAN BAHAN BEKAS DI SD NEGERI O1 PADANG AIR DINGIN

Mirda Swetherly Nurva, Tiara Fikriani

Volume 1, No. 1, April 2021 hal. 102-108

DOI Artikel : 10.46306/jub.v1i1.20

Pada gambar ini, guru memanfaatkan tutup botol untuk mengajarkan teknik perkalian . untuk hasul yang ditulis pada tutup botol, maka akan dipasangkan dengan kepala botol yang sudah ditempel pada kayu.
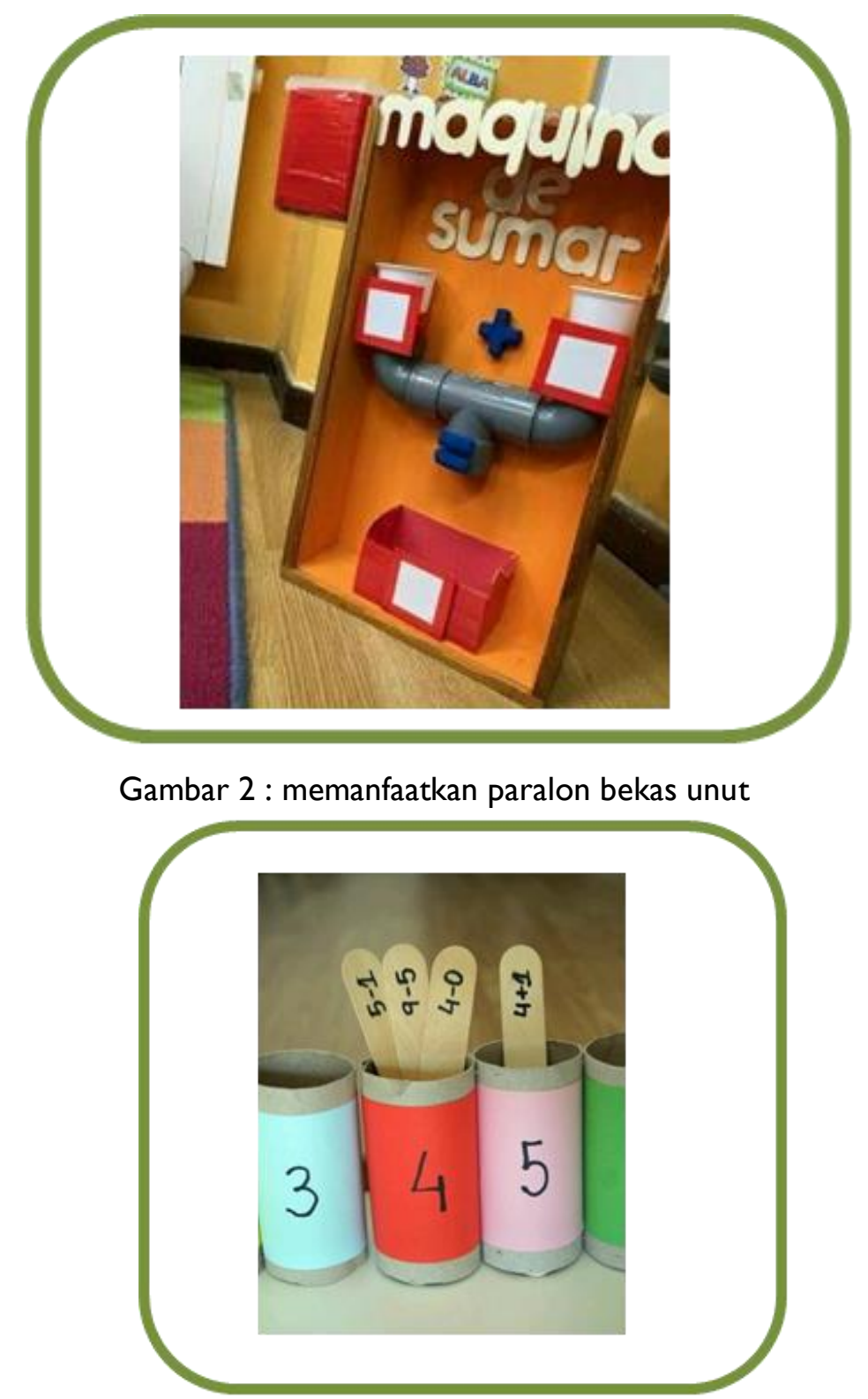

Gambar 3. Memnfaatkan stik es dalam materi penjumlahan

\section{KESIMPULAN DAN SARAN}

Peraga diharapkan menjadi dasar bagi tumbuhnya konsep berpikir abstrak bagi peserta didik, karena alat peraga tersebut dapat dimanipulasi (dapat diraba, dipegang, dipindahkan, dipasangkan, dan sebagainya), sehingga peserta didik dapat belajar secara aktif baik secara individual maupun kelompok. Dengan menggunakan media/alat peraga tersebut anak akan lebih menghayati matematika secara nyata berdasarkan fakta yang jelas dari hasil manipulasi obyek dan diharapkan anak lebih mudah memahami topik yang disajikan. 
PELATIHAN PEMBUATAN ALAT PERAGA MATEMATIKA UNTUK SEKOLAH DASAR MEMANFAATKAN

BAHAN BEKAS DI SD NEGERI O1 PADANG AIR DINGIN

Mirda Swetherly Nurva, Tiara Fikriani

Volume 1, No. 1, April 2021 hal. 102-108

DOI Artikel : 10.46306/jub.v1i1.20

SDN 0I Padang air dingin terletak cukup jauh dari ibukota kabupaten. Sehingga untuk fasilitas internet, kurang memadai. Sedangkan guru dituntut untuk selalu kreatif dan inovatif dalam pembelajaran. Hal ini yang mengharuskan guru untuk lebih kreatif memanfaatkan bahan disekitar, untuk dimanfaatkan . Namun terkendala lagi dengan minimnya pelatihan yang didapat guru secara periodic.

Oleh karena itu, TIM dari pendidikan matematika STKIP Ahlussunnah memberikan layanan kepada guru-guru, untuk memotivasi dalam menciptakan media pembelajaran. Cara dan macam penggunaan setiap alat peraga memang berbeda-beda sesuai dengan konsep materi yang harus dipahami oleh anak dan disesuaikan dengan metode pembelajaran yang digunakan. Guru harus paham dan terampil dalam pengelola alat peraga matematika yang digunakan.

Guru harus pula tahu apakah alat peraga tersebut untuk penanaman konsep atau pembinaan keterampilan. Dalam belajar matematika, Modul Matematika SD Program BERMUTU pengalaman belajar anak sangatlah penting. Pengalaman tersebut akan membentuk suatu pemahaman apabila ditunjang dengan alat bantu belajar, yang berfungsi untuk mengkongkretkan materi-materi matematika yang bersifat abstrak.

\section{UCAPAN TERIMA KASIH}

Kegiatan ini dilaksanakan pada hari Senin, tanggal 13 Juli 2020, yang dihadiri oleh kepala sekolah, majelis guru SD Negeri 0I Padang Air Dingin. Pada kesempatan ini, kami ucapkan terimakasih kepada:

1. Ketua STKIP Ahlussunnah yang mendukung kegiatan ini.

2. Ketua Lembaga Penelitian dan Pengabdian Masyarakat STKIP Ahlussunnah yang telah memberikan kemudahan dalam pelaksanan pengabdian

3. Seluruh staf akademika STKIP Ahlussunnah yang telah memberikan motivasi dalam kegiatan pelatihan ini.

4. Kepala Sekolah, Majelis Guru, dan Karyawan SD Negeri 0I Padang Air Dingin.

Semoga kegiatan pengabdian ini dapat bermanfaat bagi Guru dan siswa-siswi SD Negeri 0I

Padang Air Dingin

\section{DAFTAR PUSTAKA}

Arsyad, Azhar , Media Pembelajaran, Jakarta: Rajawali Press, $201 \mathrm{I}$.

Asmidi, A. (2020). PEMBELAJARAN KOOPERATIF BERBANTUAN ALAT PERAGA UNTUK MENINGKATKAN PEMAHAMAN MATEMATIKA SISWA. Jurnal Pembelajaran Prospektif, 4(2). doi:10.264I8/jpp.v4i2.40494

Baharudin, Teori Belajar \& Pembelajaran, Yogyakarta: ArRuzz Media, 2010. Hustandi, Cecep, Media Pembelajaran Manual dan Digital, Bogor: Ghalia Indonesia, 20II

Lubis, N. (20I5). PENINGKATAN AKTIVITAS BELAJAR MATEMATIKA DENGAN MENGGUNAKAN ALAT PERAGA DI KELAS VI SD NEGERI 088 PANYABUNGAN KABUPATEN MANDAILING NATAL. SCHOOL EDUCATION JOURNAL PGSD FIP UNIMED, 4(2), 32-42. doi: $10.24 \mid$ I 4/sejpgsd.v4i2.36I8 
PELATIHAN PEMBUATAN ALAT PERAGA MATEMATIKA UNTUK SEKOLAH DASAR MEMANFAATKAN

BAHAN BEKAS DI SD NEGERI 01 PADANG AIR DINGIN

Mirda Swetherly Nurva, Tiara Fikriani

Volume 1, No. 1, April 2021 hal. 102-108

DOI Artikel : 10.46306/jub.v1i1.20

Napfiah, S. (2019). Pembuatan Alat Peraga Matematika untuk Meningkatkan Kreativitas Mahasiswa. Jurnal Tadris Matematika, 2(I). doi:I0.2I 274/jtm.2019.2.1.3I-40

Pardossi, A. (20I8). MENINGKATKAN AKTIVITAS DAN HASIL BELAJAR MATEMATIKA MENGGUNAKAN ALAT PERAGA. Jurnal Pendidikan Matematika Dan IPA, 9(2), 28. doi:10.26418/jpmipa.v9i2.26769

Suherman, Eman, Strategi Pembelajaran Matematika Kontemporer, Bandung: JICA Jurusan Matematika UPI, 2003.

Sukarman, Harry, Penduan Penggunaan Alat Peraga Matematika untuk Sekolah Dasar, Yogyakarta: UD. Perada Pembina, 1997.

Sulistyaningsih, M., Kaunang, D. F., \& Mangelep, N. O. (2018). PKM Bagi Guru Sekolah Dasar Dalam Mengembangkan Alat Peraga Berbasis Pendekatan Matematika Realistik. MATAPPA: Jurnal Pengabdian Kepada Masyarakat, I (2), I26. doi:I0.3 I I00/matappa.vIi2.226 